\title{
Rommentar $\mathfrak{z} \mathfrak{u}$
}

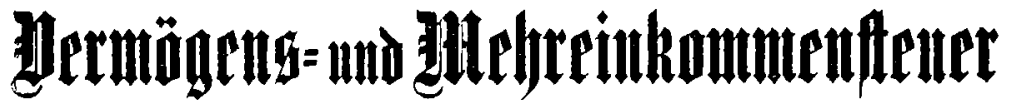 \\ 1919.}

Yon

Rudwtg $\mathfrak{B u c k}$ und Dr. Rudolf $\mathfrak{\text { Reas }}$

Reglexungstat in Düffelbori.

Rechtsanmalt in sülfeldotf.

Eriter Teil:

Bermögenszumąs= und Mehreinkommen= (Mebrgewinn=) iteuer.

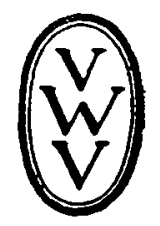

Berlin und Leipzig 1920

Beretuigung wiffeniめaftiłder Berleger

Walter be Gruyter \& $\boldsymbol{C}_{0}$.

vormals 6. I. Gölden'fhe Berlagsbanblung - J. Guttentag Derlags. buめbanding - Georg Retmer - Garl J. Irübrer - Bett \& Comp. 
